\title{
Structural and Electrical properties of Thermally Evaporated Nanostructured CuInSe Thin Films
}

\author{
A. B. Jain, Y. R. Toda, D. N. Gujarathi \\ Thin Film Lab, Department of Physics, Pratap College, Amalner - 425401 (MS) India
}

\begin{abstract}
Nano structured thin films having different thickness of CuInSe were deposited by thermal evaporation techniques, onto precleaned amorphous glass substrate at room temperature. The structural properties of films were evaluated by XRD, Scanning Electron Microscopy (SEM) and Atomic Force Microscopy (AFM). The quantitative analysis was done by Energy Dispersive Analysis for $x$-ray to determine atomic \% of the material used. The electrical transport properties of as deposited thin films have been evaluated by using four probe resistivity set up. Resistivity $\left(3.108 \times 10^{-5} \mathrm{ohm}-\mathrm{cm}\right)$, activation energy $(0.00396-0.0752$ $\mathrm{eV})$, carrier concentration $\left(1.30 \times 10^{18} / \mathrm{cm} 3\right)$, mobility $\left(1.53 \times 10^{4} \mathrm{~cm}^{2} / \mathrm{V}-\mathrm{s}\right)$ has been estimated. Thermo Electrical parameters such as Fermi energy (0.025 to $0.461 \mathrm{eV})$, absorption coefficient (0.0042 to 0.067) have been estimated. The $x$-ray diffraction analysis confirms that films are polycrystalline in nature having cubic structure with a preferential orientation along the (300) plane. The degree of such a preferred orientation was found to increase with film thickness. The lattice parameters $(a=11.53 \AA)$ and crystallite size $(D)$ were calculated and found to be $16.21 \mathrm{~nm}$. The dislocation density, the number of crystallites per unit area $(N)$ and the strain ( $(\varepsilon)$ of the films were determined. SEM investigation confirms that nano size grains were distributed almost uniformly over smooth substrate and particles were granular in nature. Large grains on top of dense bottom films were observed. The nano grains forms cluster by fusing to each other. The size of clusters was found approximately $48.04 \mathrm{~nm}$ to $235.05 \mathrm{~nm}$.
\end{abstract}

Keywords: Nano structured, XRD, SEM, AFM, activation energy, Fermi energy

\section{Introduction}

Semiconducting thin films have been extensively studied for a long time due to their significant role in modern science \& technology [1]. In recent years there has been a growing attention to ternary chalcopyrite compound $\mathrm{CuInSe}_{2}$ and its alloys [2]. Copper indium selenide (CIS) is a leading light absorbing semiconductor for thin film solar cells due to its many unique optical \& electrical properties, suitable direct band gap of 1.02 $\mathrm{eV}$ and high optical absorption coefficient $\left(>10^{5} \mathrm{~cm}^{-1}\right)$ [3,4]. CuInSe and related ternary compound semiconducting materials are known for their suitability in photovoltaic devices due to the higher absorption coefficient near the fundamental absorption edge. Of the ternary compounds CIS is considered as promising candidate for absorber based polycrystalline thin film solar cells [5]. It is the aim of the continued research to find a simplified method that will allow the deposition of stoichiometric CIS thin films using a single stage process capable of producing large area device quality material [6].

In this work we have studied the effect of thickness on the structural, surface morphological and electrical properties of thermally evaporated CuInSe thin films of different thicknesses. Structural parameters such as grain size were measured from XRD spectra and were found to depend on the film thickness. The details have been reported in this paper.

\subsection{Material Preparation}

\section{Experimental}

The CuInSe compound ingots were obtained by taking appropriate amount of $99.999 \%$ pure $\mathrm{Cu}$, In and $\mathrm{Se}$ in an evacuated quartz ampoule. The ampoule with the charge was then sealed under a pressure of $10^{-5} \mathrm{~Pa}$ and was placed in rotating furnace. The temperature of the furnace was raised gradually to $1072 \mathrm{~K}$ and left at this temperature for about $72 \mathrm{~h}$. Well mixed charges were then quenched in an ice bath [7, 8]. The CuInSe ingot was taken out from the ampoule and made into fine powder and used for film preparation.

\subsection{Synthesis and Characterization of sample}

Polycrystalline CuInSe films have been deposited by thermal evaporation technique under vacuum of about $10^{-5} \mathrm{~Pa}$. The substrate to source distance was kept $20 \mathrm{~cm}$. The samples of different thicknesses were deposited under similar conditions. The thickness of the films was controlled by quartz crystal thickness monitor model No. DTM - 101 provided by Hind-Hi Vac. Further confirmation of thickness was estimated by Tolansky's method [9] using multiple beam Fizeau fringes. The deposition rate was maintained $10-20 \AA / \mathrm{sec}$ throughout sample preparation. Before evaporation, the glass substrates were cleaned thoroughly using concentrated chromic acid, detergent, isopropyl alcohol and distilled water. 
X-ray diffractograms (Rigaku Mini flex, Japan) were obtained of these samples to find out structural information and to identify the film structure qualitatively. The scanning angle (20) range was from $20^{\circ}-80^{\circ}$ $(\mathrm{CuK} \alpha$ line). Surface morphological studies of the thermally deposited CuInSe thin films were done using the Scanning Electron Microscope (Zeiss EVO 50) operating with an accelerating voltage $10 \mathrm{kV}$ and Atomic Force Microscopy (AFM). The quantitative compositional analysis of the CIS films was carried out by EDAX (Energy dispersive X-ray Analyzer) technique attached with the SEM. The resistivity of samples was measured by four probe technique using a function of thickness and temperature. The thermo electric power of samples was measured by TEP set up using model no. DMV - 001, "Scientific Equipments, Roorkee", as a function of thickness and temperature.

\subsection{XRD Analysis of CuInSe Thin Films}

\section{Results and Discussions}

Figure 1 shows the XRD pattern of CuInSe thin films having thickness of 1500 A.U. The $2 \theta$ peak observed at 23.6, 48.5, 52 and 65 which correspond to the (300), (611), (622) and (810) planes of reflections. The XRD spectrum revels that the films are polycrystalline in nature and cubical structure. The average grain size is calculated $16.21 \mathrm{~nm}$ [10] by Scherrer's formula. The lattice parameters $\mathrm{a}=\mathrm{b}=\mathrm{c}$ have been determined 11.53 matches with the JCPD data card (79-1809).

The dislocation density, the number of crystallites per unit area $(\mathrm{N})$ and the strain $(\varepsilon)$ of the films were determined and found to be $3.8056 \times 10^{15}$ lines $/ \mathrm{m}^{2}, 3.5214 \times 10^{16}$ and 0.00111 lines ${ }^{-2} \mathrm{~m}^{-4}$ respectively [11].

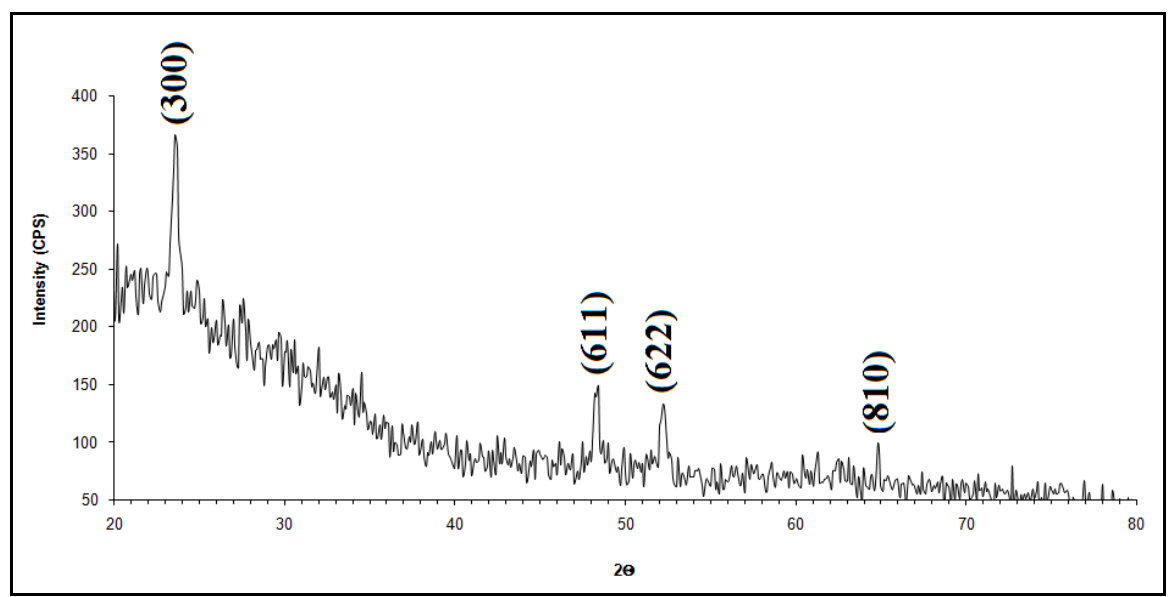

Figure 1: XRD pattern of CuInSe

\subsection{AFM Analysis of CuInSe Thin Films}

Figure (2 and 3) shows AFM 2D and 3D images of CuInSe thin film having thickness 2000Á and $3000 \AA$ r respectively. The surface topography is composed of clusters of varying sizes with irregular shapes. The irregular shapes of grains suggest that at low substrate temperature the K.E. is not sufficient for the coalescence of the grains [12]. The film surface is found to be homogeneous, without any void and crack. In the grown sample particles have niddle shape formation of different sizes. From both figure $(2-5)$, it is clear that as thickness increases the density of also increases. The roughness of the film surface is small and found to be 16 nm.
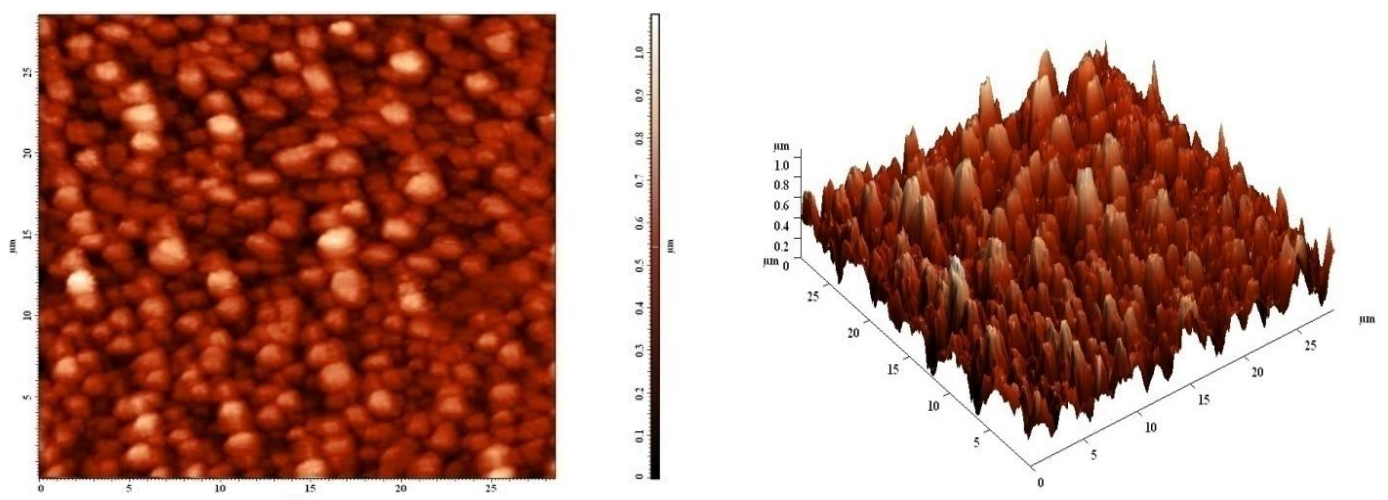

Figure 2: AFM photograph of 2D image. Figure 3: AFM photograph of 3D image. 


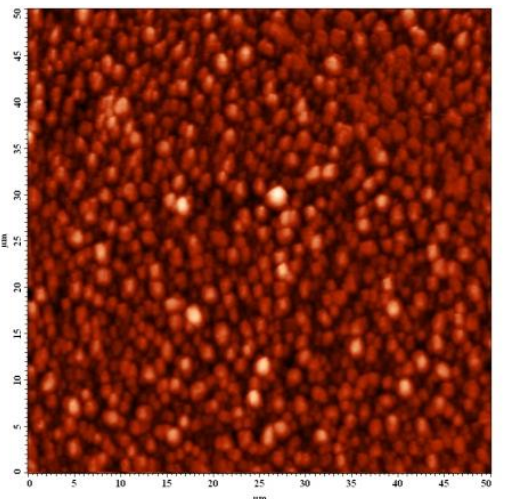

Figure 4: AFM photograph of 2D image.

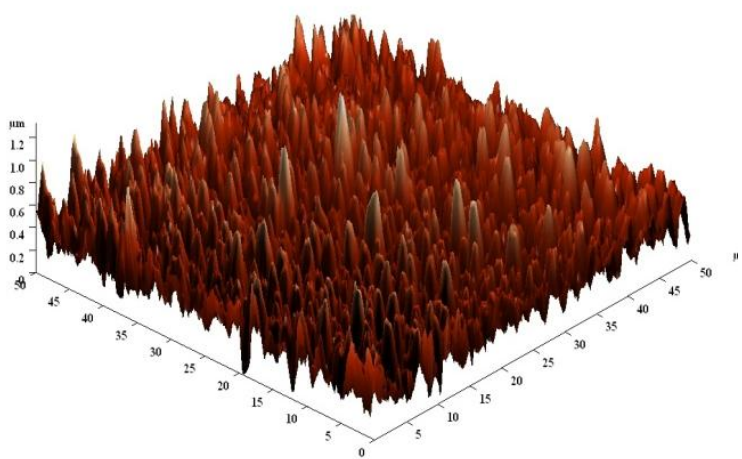

Figure 5: AFM photograph of 3D image.

The grain size analysis was done with the help of AFM as shown in figure 6. The Histogram shows the area of grains with respect to frequency. The total grains collected are 441 and the area is found to be decreasing for the scan area $1 \times 1$ micron ${ }^{2}$ and then decreases.

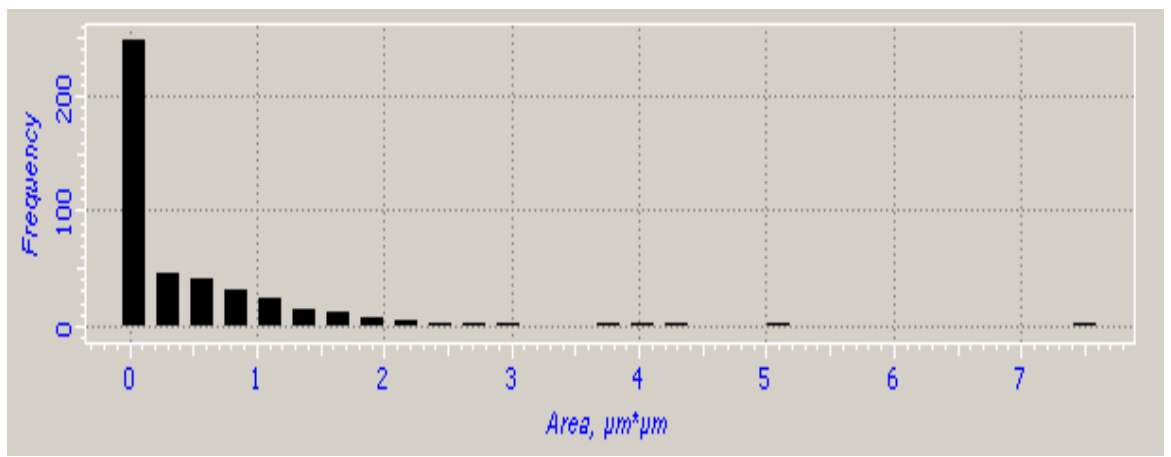

Figure 6: Histogram of $\mathrm{CuSe}$ thin film

\subsection{Scanning Electron Microscopy of CuInSe thin film}

Figure 7 and 8 shows SEM images of CuInSe thin film of thickness $1500 \AA$ with various magnifications $70.00 \mathrm{~K}$ and $125.00 \mathrm{~K}$. The SEM image of CuInSe thin film show that the film is uniformly deposited and free from any microscopy defects like holes and cracks. Nano size grains were distributed almost uniformly over smooth substrate. The size of clusters was found approximately $30.67 \mathrm{~nm}$ to $55.08 \mathrm{~nm}$.
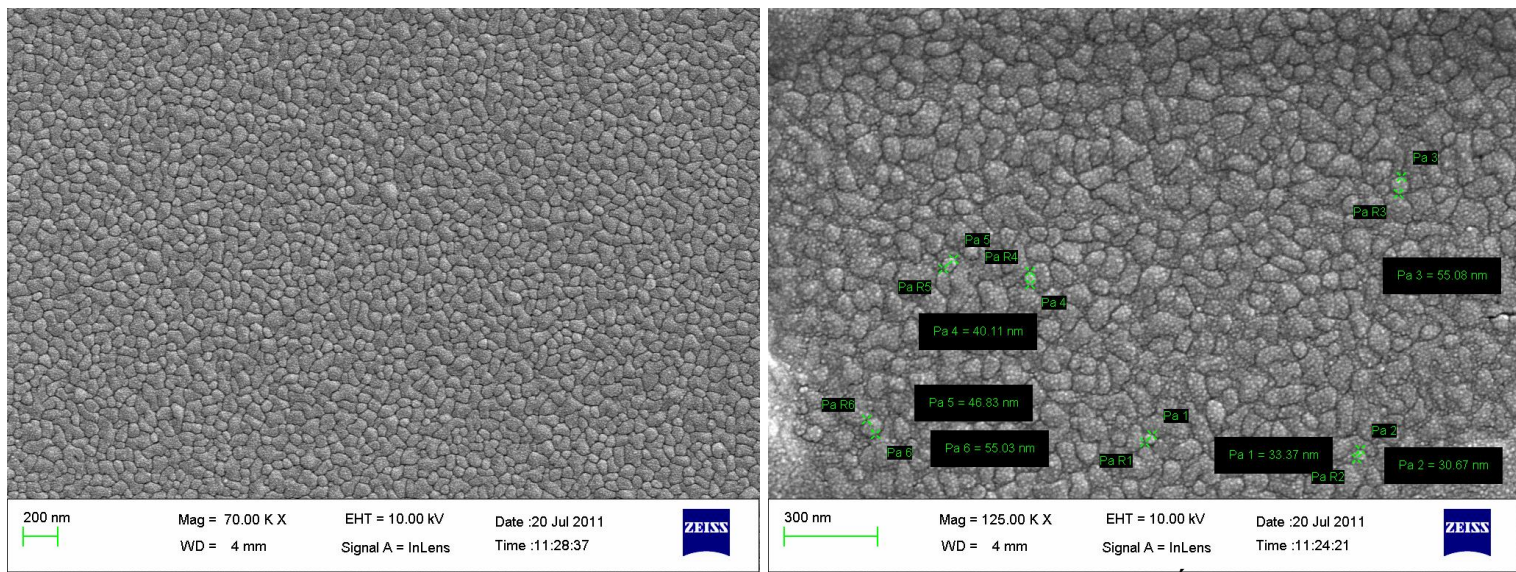

Figure 7-8: SEM image of CuInSe thin film thickness $1500 \AA$

Figure $(9-11)$ shows SEM images of CuInSe thin film of thickness $3000 \AA$ with various magnifications $10.74 \mathrm{~K}, 70.00 \mathrm{~K}$ and $125.00 \mathrm{~K}$. The SEM image of CuInSe thin film show that the film is uniformly deposited over the substrate and free from any microscopy defects like holes and cracks. Large grains on top of dense bottom films were observed. Nano size grains were distributed almost uniformly over smooth substrate. The nano grains forms cluster by fusing to each other. The size of clusters was found approximately $48.04 \mathrm{~nm}$ to $235.05 \mathrm{~nm}$. 

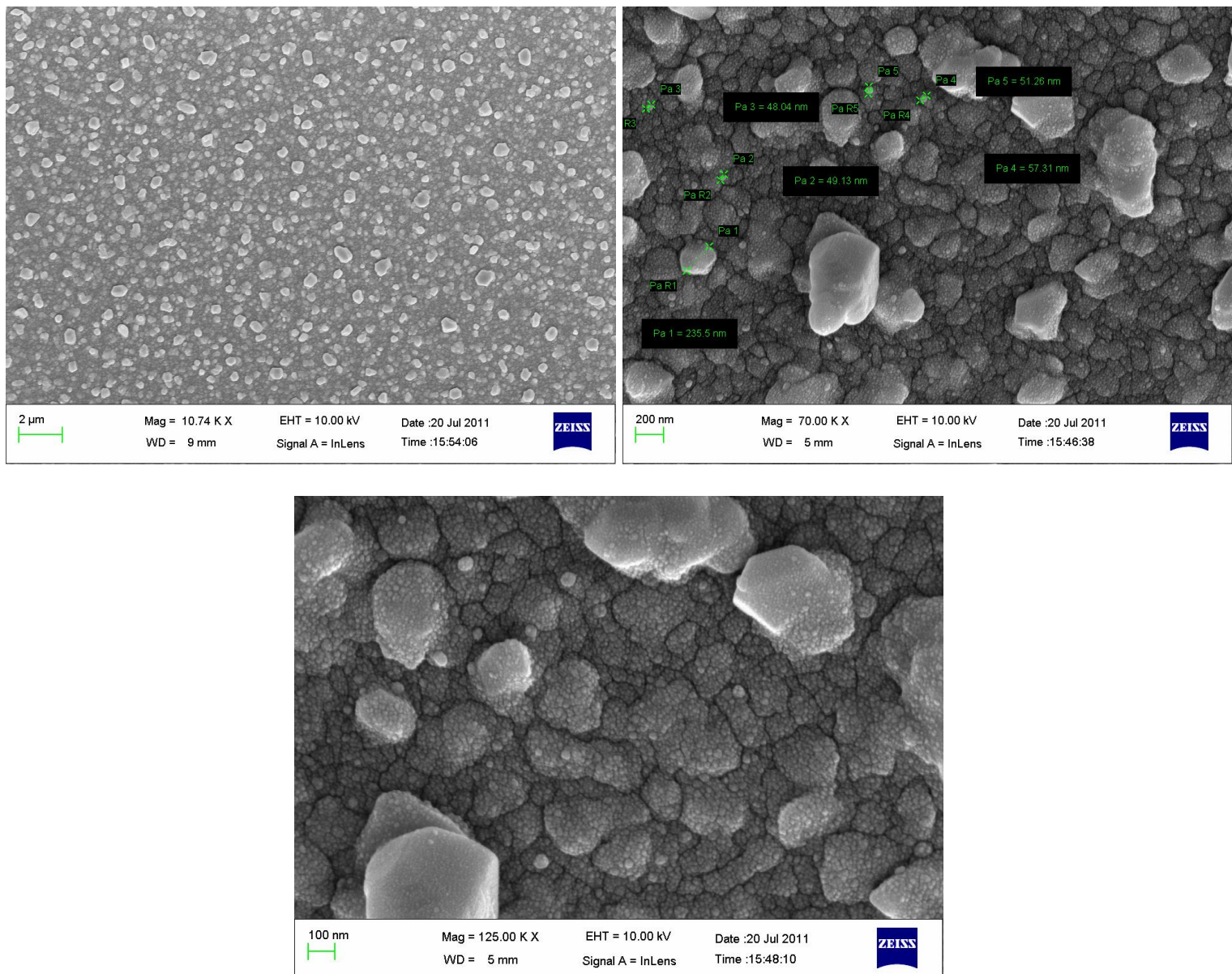

Figure 9-11: SEM images of CuInSe thin film thickness $3000 \AA ̊$

\subsection{EDAX Analysis of CuInSe Thin Films:}

Atomic concentration of the constituent elements present in the samples was determined using EDAX, recorded on EDAX (Genesis MX2) spectrometer attached to the SEM. The EDAX spectrum of as grown sample is shown in Fig. 12. The atomic concentration of $\mathrm{Cu}$, In and $\mathrm{Se}$ is found to be 5.47, 94.20 and 0.32 percent respectively. EDS spot analysis on these grains shows that films are indium rich.

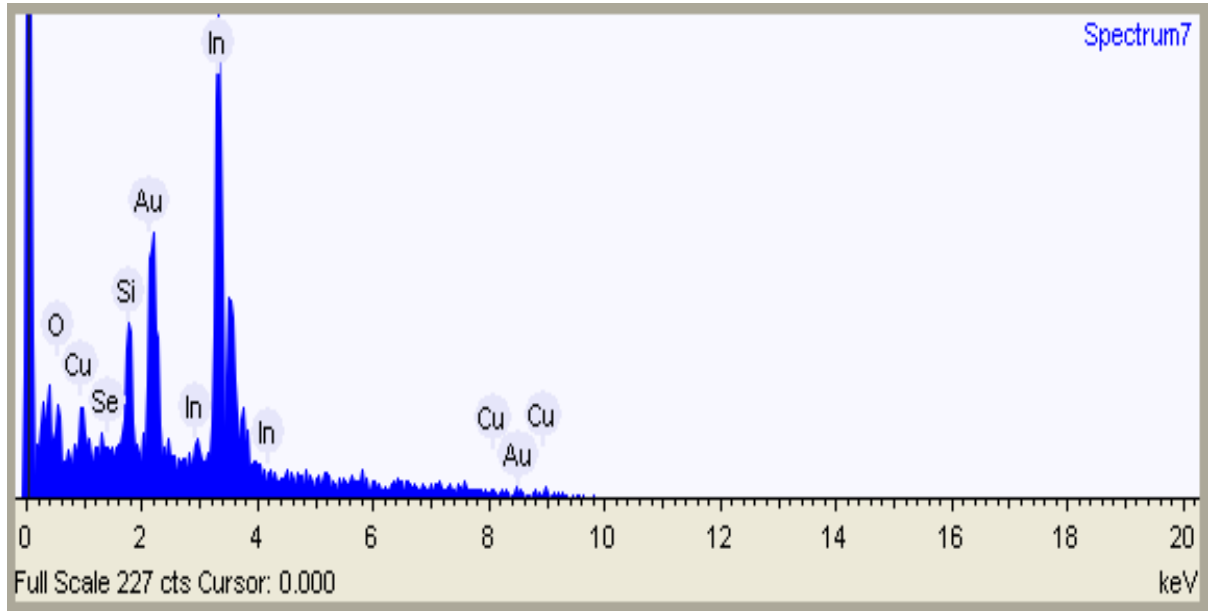

Figure 12: EDAX Spectra of CuInSe thin film

The EDAX spectrum confirms that the presence of element. The other peaks were found due to the gold coating and glass substrate, excepted this the recorded EDAX spectrum informs that there is no evidence of other impurity. 


\subsection{Electrical and Thermo electrical properties of CuInSe films}

\subsubsection{Resistivity Measurement of CuInSe Thin Films}

The resistivity of CuInSe thin films of different thicknesses 500 - $2000 \AA$ was measured for all samples at room temperature. The graphical representation of probe voltage versus probe current for different thicknesses is as shown in Fig. 13. The plot of resistivity as a function of thickness indicates that the resistivity of films increases as thickness increases. This fact is further confirmed from the slopes and intercepts of these plots (Fig. 14, $15 \& 16$ ), bulk resistivity $\left(\rho_{0}\right)$ and the mean free path of the charge carrier in bulk material were evaluated and $\rho_{0}=3.108 \times 10^{-5} \mathrm{ohm}-\mathrm{cm}, \lambda_{0}=343.2003 \AA$.

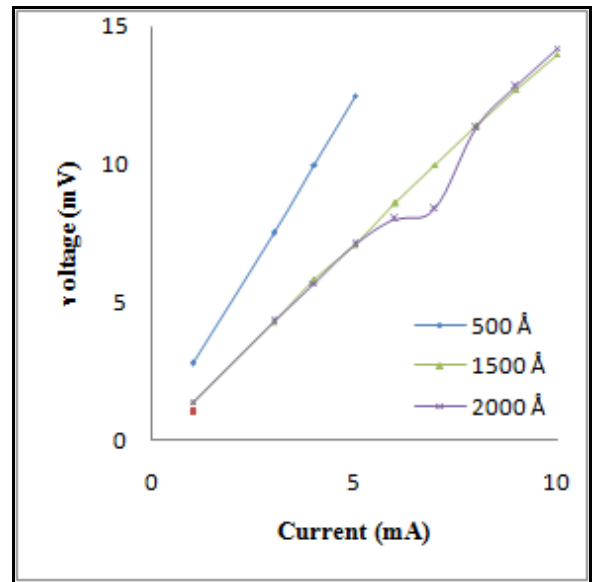

Fig. 13: I-V Characteristics of CuInSe thin films

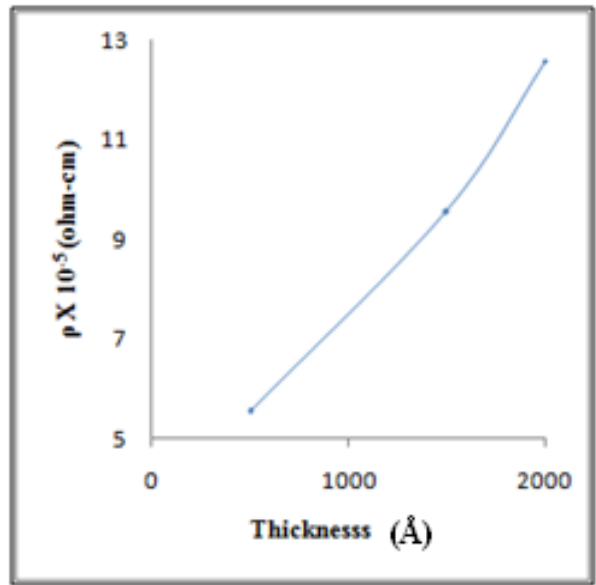

Fig. 14: Plot of Resistivity versus Thickness

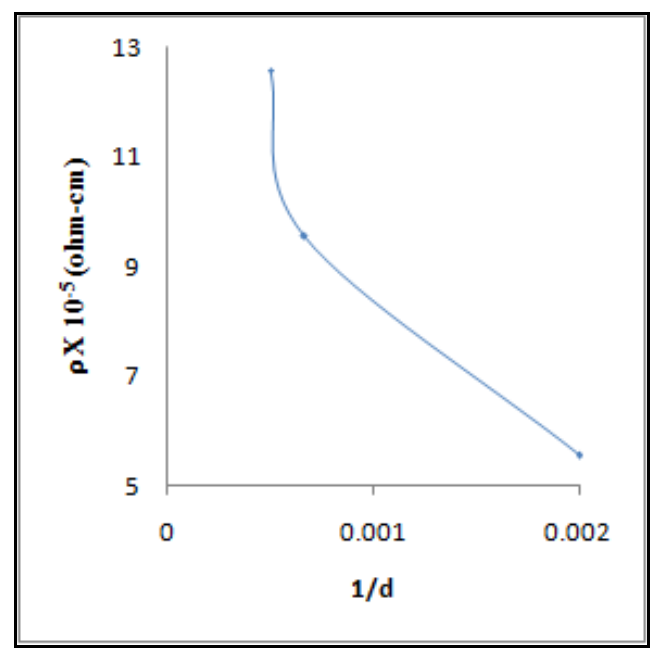

Fig. 15: Plot of Resistivity versus 1/ Thickness 


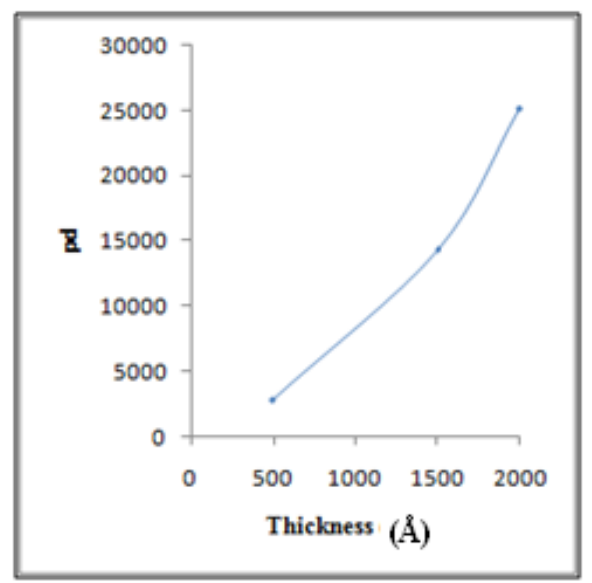

Fig. 16: Plot of $\rho d$ versus Thickness

Using these values, charge carrier concentration was estimated as $\mathrm{n}=1.3063 \times 10^{18} / \mathrm{cm}^{3}$ [13], and mobility was found $\mu=1.5394 \times 10^{4} \mathrm{~cm}^{2} / \mathrm{V}$-s (Table 1 ).

Table 1: Estimated parameters of CuInSe thin films

\begin{tabular}{|l|l|}
\hline Bulk Resistivity $\rho_{0}(\mathrm{ohm}-\mathrm{cm})$ & $3.108 \times 10^{-5}$ \\
\hline Mean free path $\lambda_{0}(\AA)$ & 343.2 \\
\hline Carrier Concentration $(\mathrm{n}) / \mathrm{cm}^{3}$ & $1.3063 \times 10^{18}$ \\
\hline Mobility $(\mu) \mathrm{cm}^{2} / \mathrm{V}-\mathrm{s}$ & $1.5394 \times 10^{4}$ \\
\hline
\end{tabular}

The measurement of temperature dependence of electrical resistivity showed that CuInSe films always have positive temperature coefficients [9]. The plots of $\log \rho$ as a function of reciprocal of absolute temperature $(1 / \mathrm{T})$ are represented in Fig 17. The electrical conductivity varies linearly with temperature. And so the electrical data fits the reaction $\rho=\rho_{0}\left(\frac{-E_{\Omega}}{K T}\right)$, therefore the conductivity is attributed to thermal excitation of charge carriers from grain boundaries to the neutral region of grains. The activation energy associated with thermally deposited CuInSe films at higher temperature can be attributed to thermally activated process. Similar characteristics have been reported for CuInSe films by earlier worker [14-15, 4, 16].

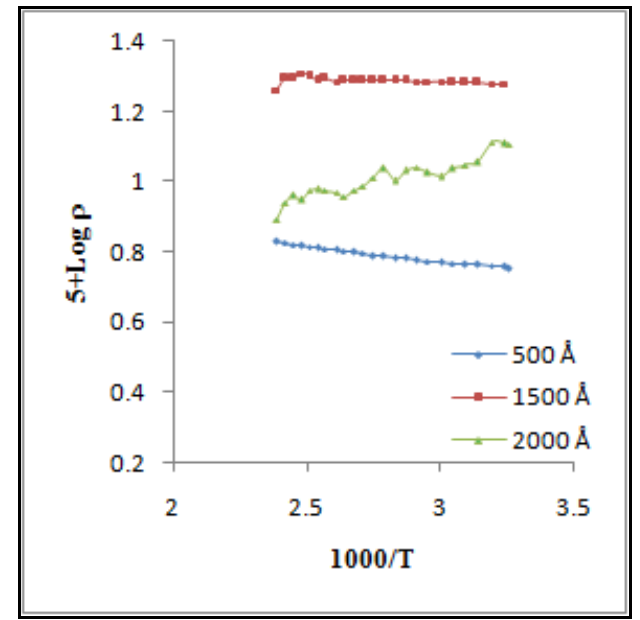

Fig. 17: Plot of log of resistivity vs. reciprocal of thickness

These plots are linear for each thickness. The activation energy is represented in Table 2 .

Table 2: Experimental values of activation energy for CuInSe Films

\begin{tabular}{|l|l|}
\hline Thickness & Activation Energy \\
\hline 500 & 0.00396 \\
\hline 1500 & 0.0752 \\
\hline 2000 & 0.0336 \\
\hline
\end{tabular}




\subsubsection{Thermo Electric Power Measurement of CuInSe Thin Films}

The graphical representation of thermo e.m.f verses change in temperature (Seebeck coefficient versus change in temperature) for different thickness of CuInSe thin films were shown in Fig. 18 and Fig. 19 also the graphical representation thermo e.m.f verses $1000 / \mathrm{T}$ and Seebeck coefficient versus 1000/ $\Delta \mathrm{T}$ for different thicknesses of thin films are as shown in Fig 20 and Fig. 21. From these graph the Fermi energy and absorption coefficient are calculated and represented in Table 3. The Fermi energy of CuInSe thin films is thickness dependant. TEP measurement shows the deposited films are of P-type semiconducting in nature. The positive sign of TEP suggests that conduction should occur predominantly due to holes, which established the $p$-nature of the CuInSe thin films, which indicates that conduction is primarily due to holes.

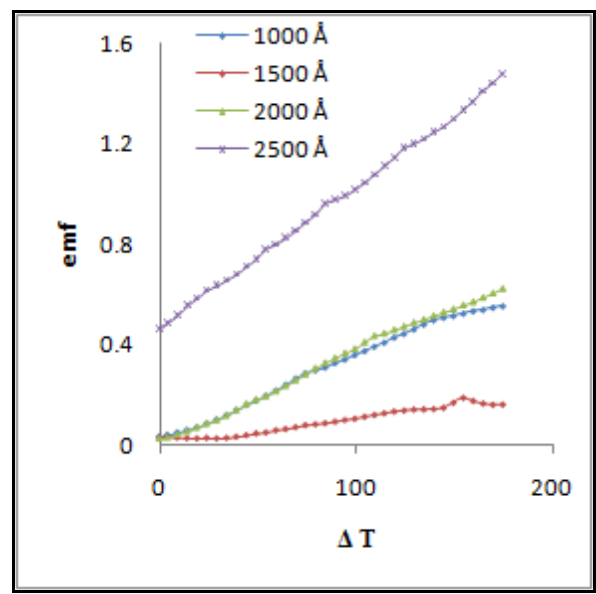

Fig. 18: Plot of thermo emf Vs. Del T

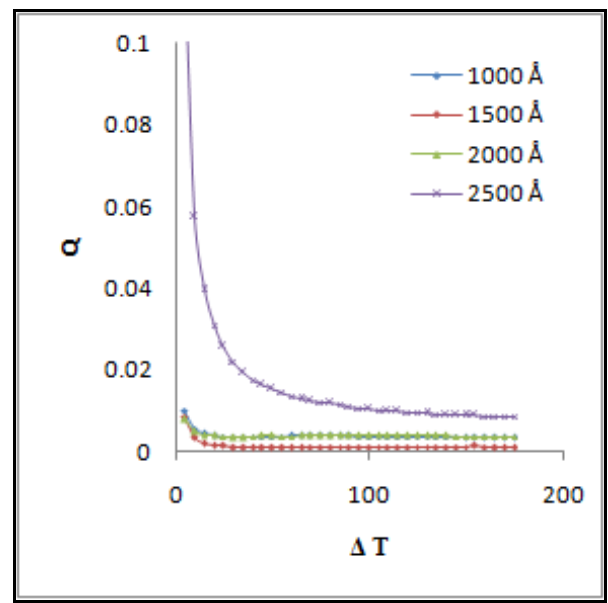

Fig. 19: Plot of Seebeck Coefficient Vs. Del T

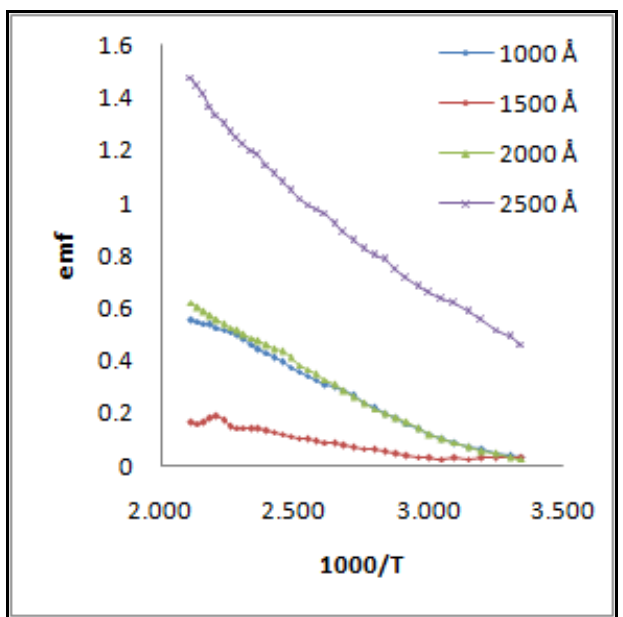

Fig. 20: Plot of Thermoemf Vs. 1000 / T 


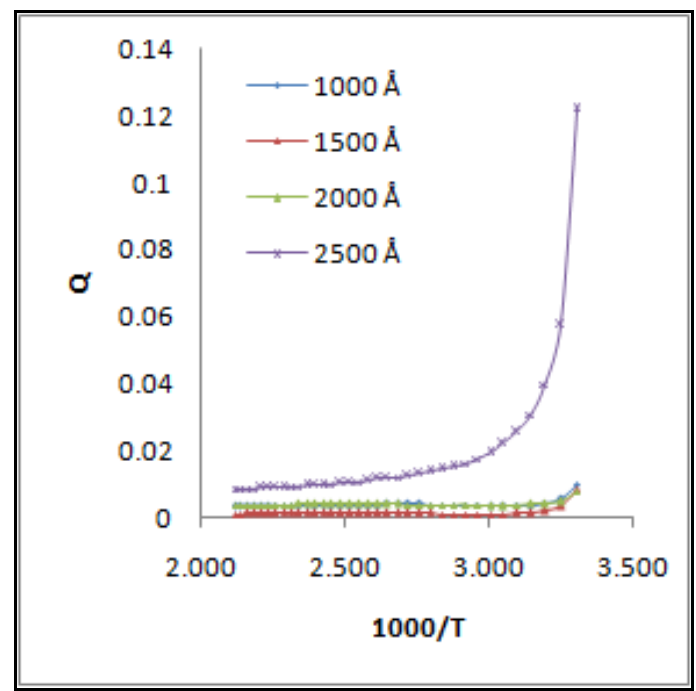

Fig. 21: Plot of Seebeck Coefficient Vs. 1000 / T

Table 3: Estimated Parameters from TEP (CuInSe Films)

\begin{tabular}{|l|l|l|}
\hline Thickness $(\mathbf{A})$ & Fermi Energy $(\mathbf{e V})$ & Absorption Coefficient \\
\hline 1000 & 0.025 & 0.0042 \\
\hline 1500 & 0.031 & 0.0018 \\
\hline 2000 & 0.102 & 0.001 \\
\hline 2500 & 0.461 & 0.0679 \\
\hline
\end{tabular}

\section{Discussions}

CIS thin films of different thickness have been deposited successfully on glass substrate with different thicknesses. XRD confirms that the structure of the film is polycrystalline in nature and having cubical structure. From SEM study it is observed that deposited CIS film were homogenous and granular structure with nano crystalline in nature. The particle size varying from $48.04 \mathrm{~nm}$ to $235.05 \mathrm{~nm}$. From AFM study it is observed that surface image is homogeneous and well connected grains. Fermi energy was evaluated as 0.025 to $0.461 \mathrm{eV}$ and absorption coefficient was found to be 0.0042 to 0.067 . Activation energy was found to be 0.00396 to 0.0752 $\mathrm{eV}$; hence the CIS can be used in development of efficient photovoltaic application in the next phase of work.

\section{References}

[1]. K. Senthil, D. Nataraj, K. Prabakar, Materials Chemistry and Physics 58, 1999, 221-226.

[2]. Feng Kang, Jianping Ao, Guozhong Sun, He Yun Sun, Journal of Alloys and Compounds 478, 2009, $125-127$.

[3]. Weidong Wang, Zhengguo Jin, Hui Liu, Haiyan Du, Materials Letters 65, 2011, 2895-2898.

[4]. A. H. Moharram. M. M. Hafiz, A. Salem, Applied Surface Science 172, 2001, 61-67.

[5]. P. Malar, V. Damodara Das, S. Kasiviswanathan, Vacuum 75, 2004, 39-49.

[6]. Sreejith Krthikeyan, Arthur E. Hill, Richard John S. Cowpe, D. Pilington, Thin Solid Films 519, 2011, 3107-3112,

[7]. U. P. Khairnar, P. H. Pawar, G. P. Bhavsar, Cryst. Res. Technol, 37(12), 2002, 1293 - 1302

[8]. K. S. Chaudhari, Y. R. Toda, A. B. Jain, D. N. Gujarathi, Archives of Applied Science Research, 3(2), $2011,292-296$.

[9]. S.R. Gosavi, N. G. Deshpande, Y. G. Gudage, Rampal Sharma, J. Alloys \& Compounds, 448, $2008,344-348$.

[10]. S. Agilan, D. Mangalraj, Sa. K. Narayandass, G. Mohanrao, S. Velumani, Vaccum 84, 2010, 1220-1225.

[11]. M. P. Kannan, R. Balasundaraprabhu, S. Jayakumar, P. Ramanathaswamy, Solar Energy Materials, and Solar Cells, 81, 2004, 379395.

[12]. N.M. Shah, C. J. Panchal, V. A. Kheraj, J. R. Ray, M. S. Desai, Solar Energy, 83, 2009, 753-760.

[13]. Shijemi Kohiki, Mikihiko Nishitani, Takayuki Negami, Takahiro Wada, Masahiro Sakai, Yohichi Gohshi, Physical Review, 46, No. 12, 1992, 7911-7914.

[14]. S. Agilan, D. Mangalaraj, Sa. K. Nrayandaas, G. Mohan rao, S. Velumani, Vaccum, 84, 2010, $1220-1225$.

[15]. Schmidt J. Roscher HH, Labusch R, Thin Solid Films, 251, 1994, 116-120.

[16]. Tembhurkar Y.D, Hirade J. P., Thin Solid Films, 215, 1992, 65-70. 